\title{
Jogando com a comida: MasterChef e os recursos televisuais que tornam espetacular uma atividade ordinária
}

\section{Carlos Eduardo Marquioni e Fernando Andacht}

\section{Resumo}

0 artigo analisa o programa MasterChef enquanto formato híbrido entre 0 reality show e o talent show. Aborda-se seu sucesso como associado a um letramento televisual que, em seu estágio atual, proporciona exposição à audiência da artificação culinária contemporânea. Além da análise semiótica e imanente, usa-se material obtido em entrevistas com membros da produção da primeira edição brasileira. 0 resultado seria que 0 aspecto culinário prático não constituiria a principal atração do programa. 0 formato possuiria cinco componentes que explicariam sua popularidade, entre eles destacam-se as ordálias da identidade dos participantes em provas de resistência psicológica tanto quanto culinária.

\section{Palavras-Chave}

Reality Show; Letramento; Semiótica Indicial.

Carlos Eduardo Marquioni I cemarquioni@uol.com.br Doutor em Comunicação e Linguagens pela Universidade Tuiuti do Paraná (UTP), Brasil. Professor do PPGCom da UTP, editor executivo da revista Interin e membro do Grupo de Pesquisa INCOM (CNPq).

Fernando Andacht I fernando.andacht@fic.edu.uy Doutor em Filosofia pela Bergen University, Bergen, Noruega. Professor do Departamento de Teoria e Metodologia da Facultad de Información y Comunicación da Universidad de la República, Montevidéu - Uruguai. Professor do PPGCom da UTP, Brasil.
A franquia televisual de competição gastronômica MasterChef (daqui por diante $M C$ ) é um programa que pode ser classificado como um caso de sucesso inquestionável: "[p]roduzido em mais de 34 países do mundo, e transmitido em mais de 200 territórios [...] [,] consistentemente ocupa 0 topo [dos índices de] audiência em cada território [onde vai ao ar]" (SHINE GROUP, $2015)^{1}$. Ao considerar o caso das produções locais que compõem o corpus deste artigo (Brasil e Argentina), o cenário de sucesso também pode ser observado: no Brasil, os índices de audiência da produção televisiva ${ }^{2}$ resultaram inclusive na veiculação com breve intervalo de tempo entre temporadas ${ }^{3}$; na edição argentina, o programa foi apontado como "um dos favoritos da audiência" (STILETANO, 2015).

Investigando alternativas que auxiliem a analisar esse fenômeno de mídia, os autores propõem uma série de três artigos (dos quais este é 0 primeiro), os quais apresentam algumas hipóteses no sentido de compreender qual é o mecanismo midiático e semiótico subjacente que explicaria 0 sucesso do programa em escala mundial. Como 
mencionado, são utilizados como corpus neste artigo os episódios da segunda edição das versões brasileira e argentina de $M C$ (ambas veiculadas no ano de 2015). Este recorte metodológico pode, inicialmente, sugerir que haja uma regionalização (sul-americana) para as análises; contudo, é importante observar que se trata de uma produção em formato de franquia - logo, que está sujeita a instruções normatizadas. A afirmação é atestada por Daniela Abade (roteirista da primeira temporada de MasterChef Brasil); em entrevista, a profissional citou a existência de uma série de manuais de instrução relacionados à produção dos programas da franquia (que, aparentemente para reforçar o caráter de estabilidade associada a esses manuais para a produção, são referenciados como bíblias): "são pelo menos vinte bíblias que a gente recebe" (ABADE, 2014) ${ }^{4}$. Desta forma, considera-se que, apesar do recorte adotado, as análises e reflexões realizadas poderiam ser expandidas para programas de outras localidades - ainda que existam adaptações locais que parecem ser definidas não apenas para abordar aspectos culturais locais (como pratos típicos da localidade onde ocorreu a produção de $M C$, o que pode, eventualmente, contribuir com o sucesso do programa via estabelecimento de reconhecimento/identidade), mas também em função de características de apresentação do programa.

Como exemplos de adaptações em relação a pratos típicos, podem ser citadas a prova da comida nordestina (episódio 11 da segunda temporada brasileira) e a prova do churrasco argentino (episódio 13 da segunda temporada argentina) - ainda que, em ambos os programas, existam também provas relacionadas a preparar pratos usualmente do que poderia ser considerada uma cozinha internacional (o que, eventualmente, auxilia a venda das produções locais da franquia em âmbito global). De fato, a tensão entre a existência das bíblias e as adaptações locais habilita considerar $M C$ um programa tanto global quanto "glocal" (ROBERTSON, 1995).

No que diz respeito a adaptações associadas a características de apresentação, pode ser citado

Para ilustrar o sucesso do programa, pode ser citado o que fora referenciado como sua "onipresença" (BR00KER, 2015) quando, em matéria veiculada no jornal inglês The Guardian, Charlie Brooker perguntou a seus leitores se eles teriam "visto MasterChef recentemente"; o próprio colunista respondia em seguida que, obviamente, o público teria assistido ao programa, mesmo se tentasse evitar vê-lo "porque ele $[M C]$ está sempre ali, como o céu ou o chão ou aquela pele que envolve você. MasterChef domina a grade de programação [...]. Cozinhar não poderia ficar mais onipresente do que isso" (BR00KER, 2015, grifo nosso).

0 primeiro episódio da segunda temporada brasileira tivera aumento de $40 \%$ de público em relação à estreia do ano anterior ('MASTERCHEF' REESTREIA, 2015). Dados divulgados após a final da segunda temporada informaram "um crescimento de $60 \%$ [de audiência] em relação à primeira" (FINAL, 2015).

A primeira edição brasileira da franquia foi veiculada entre 02 de setembro e 16 de dezembro de 2014 na Rede Bandeirantes; apenas cinco meses após a data da transmissão do programa final da primeira temporada (em 19 de maio de 2015), a emissora iniciou a apresentação semanal da segunda temporada (MASTERCHEF BR, 2015).

Para uma visão geral do programa (inclusive dos quadros típicos), consulte (MARQUIONI; OLIVEIRA, 2015b). 
o caso da jornalista e apresentadora da edição brasileira da franquia, Ana Paula Padrão, que recebeu algumas autorizações especiais por parte da franquia: ela

conversa com a família [do participante] [...]. Tem outra coisa que ela está fazendo e que em nenhum outro lugar do mundo acontece [...]. A Ana Paula sobe no balcão [mezanino que faz parte do cenário do programa] [...] e conversa com eles [os participantes]. 0 balcão era um lugar sagrado até então para a Shine [detentora dos direitos da franquia], onde só ficavam os competidores que estão imunizados (ABADE, 2014, grifo nosso).

Para argumentar em relação à autorização para 0 acesso ao mezanino, Abade menciona inclusive um dos aspectos que será tratado adiante neste artigo como chave para o sucesso da franquia (e que são relacionados ao aspecto emocional do formato).

A roteirista diz que, em conversa com a equipe de produção ainda no período de estudo das bíblias para aplicação das instruções da franquia na produção brasileira (mas já com a definição que Ana Paula Padrão seria a apresentadora local do programa), sugeriu:

vamos colocar a Ana Paula [no balcão], que é 0 momento em que ela vai conseguir puxar a história [dos participantes imunizados], a gente vai dar uma função legal para ela, ela se aproxima dos participantes, a gente consegue puxar mais histórias e mais coisas emocionalmente, e deu certo. Se fosse outro apresentador, se fosse outra pessoa, talvez eu tivesse dúvida. Mas como também eu já conhecia a Ana Paula [...] [sabia] que ela teria inteligência para desempenhar esse papel. Eu acho que funcionou. Foi um dos acertos que a gente teve (ABADE, 2014, grifos nossos).
Em uma tentativa de complexificar a afirmação oficial, segundo a qual o sucesso de $M C$ estaria associado ao fato de o programa ser um "formato altamente adaptável que toca em um apetite global [da audiência] por observar pessoas comuns realizarem seu sonho de alcançar algo extraordinário" (SHINE GROUP, 2015), este primeiro artigo da série aborda a franquia sob 0 aspecto que parece constituir o nível mais particular/específico de análise possível para a produção: $M C$ é considerado um formato que faz parte do gênero reality show; esta classificação do programa é válida também para os próximos dois artigos da série.

Neste primeiro artigo, são analisados então os componentes do programa que fazem parte da produção de TV, englobando a espécie de preparação ou aprendizado cultural que parece ter sido estabelecido a partir de outros programas (que orientam o público em relação a como assistir e entender $M C$ ), preparação essa associada ao uso de elementos típicos de produções de telerrealidade. Neste último caso, para contribuir com a compreensão e explicar a poderosa atração exercida pelo programa $M C$, é referenciada uma pesquisa prévia sobre um reality show que se tornou emblemático, o estandarte real da frota de desembarque dessa classe de produção televisual que conquistou o mundo no início do século XXI, depois que surgiu, de modo modesto e inesperado, no canal a cabo holandês Veronica: o programa Big Brother (a partir daqui $B B$ ), produzido pela 
companhia Endemol (ANDACHT, 2002; 2003; 2004). Os programas do gênero reality show constituem o que pode ser analisada como uma fusão entre o documentário e a ficção seriada (ANDACHT, 2003, p. 18); enquanto subgênero, esses programas podem ser classificados como "melocrônica juvenil da ordem interacional" (ANDACHT, 2003, p. 68). Ainda que 0 termo juvenil tenha sido utilizado para referenciar os participantes majoritários das primeiras edições e também a maior porção de audiência em muitos países (HILL, 2002) dos programas BB Brasil e Gran Hermano (na Argentina e no Uruguai) quando da realização da pesquisa (e o público de $M C$, potencialmente, abrange uma faixa etária mais ampla do que a de $B B$ ), os aspectos melodramático e interacional são, indubitavelmente, observáveis em $M C$ (ainda que de forma distinta, conforme tratado adiante). Vale afirmar ainda também que os programas do gênero são frequentemente referenciados como jogos (ou programas de competição).

0s próximos dois artigos da série investigam hipóteses para o sucesso do programa através de características mais gerais, considerando-0 enquanto alternativa para acessar uma intimidade familiar (tal acesso seria materializado através dos solilóquios realizados no programa) e negociar afetos em tempos de insegurança e necessidade de permanência nos limites domésticos. Procura-se, assim, com o conjunto dos três artigos propostos, realizar análises que partem de um nível mais específico (no caso do presente texto, que aborda o programa enquanto gênero televisual) e expandem para um contexto mais geral, ampliando as reflexões ao complexificar o cenário cultural do momento no qual o programa tem sido produzido, veiculado e assistido.

A capilaridade do recorte no presente artigo tem como resultado o fato de que as análises comentam, mas não avaliam detalhadamente em que medida 0 destaque que tem sido atribuído ao ato de cozinhar, que é objeto de encenação televisiva em escala global na contemporaneidade, contribui para o sucesso de $M C$. Desta forma, ainda que se considere neste trabalho que 0 ambiente da cozinha (incluindo a comida propriamente dita) esteja passando por uma forma de "artificação" (a qual, em termos midiáticos, eventualmente pode estar influenciando na redefinição dos produtos televisuais que possuem como conteúdo a culinária), a avaliação aprofundada do tema é realizada em texto futuro.

Em relação ao que seria a preparação cultural para assistir $M C$, é possível considerar 0 funcionamento de um aprendizado com a veiculação de dois tipos de programa prévios que proporcionaram tutoria (HARTLEY, 2008, p. 189) ao público, uma espécie de "letramento' dos 
espectadores no formato" (HARTLEY, 2008, p.

189) ${ }^{6}$. A audiência teria, então, sido capacitada para assistir ao programa (não apenas a cada novo episódio veiculado, mas também) na duração, a partir de duas fontes televisuais principais que justificam a decisão neste artigo de caracterizar $M C$ enquanto produto televisual híbrido, resultante de uma mistura entre 0 ato corriqueiro de cozinhar (cujo aprendizado televisual ocorrera via programas de receita, veiculados desde os primórdios da televisã $0^{7}$ ) e uma tendência contemporânea da busca pelo factual (com aprendizado televisual estabelecido via os reality shows). Pode-se inferir que ambos os tipos contribuíram para que o público assista, entenda e, sobretudo, aprecie a especificidade do formato $M C$ na contemporaneidade. Enquanto os programas de receita naturalizaram cenas televisivas de pessoas preparando alimentos de modo didático e claro, os reality shows forneceram 0 que se considera aqui os temperos metafóricos do programa relacionados à produção de TV: analogamente ao ato de cozinhar no cotidiano (quando o uso literal e real de temperos é fundamental no sentido em que podem provocar uma mudança radical na experiência do comensal), considera-se aqui que, no caso de $M C$, se alguns desses temperos metafóricos fossem removidos, o programa se tornaria completamente dessaborido, seria apenas mais um programa culinário na TV, sem 0 alto impacto imaginativo-sensorial de $M C$.

Desenvolve-se, então, neste primeiro artigo da série, uma hipótese segundo a qual 0 sucesso do programa enquanto formato televisual vinculado ao gênero reality show estaria associado tanto a uma cuidadosa e reiterada preparação da audiência ocorrida culturalmente (a partir de referências anteriores), quanto ao uso de recursos da produção de programas de TV que auxiliariam a criar um estado de atenção e de tensão que torna espetacular uma atividade humana banal de quase "invisibilidade" (MILLER, 2010, p. 51) - no sentido em que é dada

Sobre letramento, é necessário observar que os "romanos [...] elaboraram o conceito de litteratus, 'o homem de letras', ou seja, um leitor de letras, e também industriaram o seu oposto, illiteratus, um homem sem nenhuma cultura letrada" (HAVELOCK, 1994, p. 46-47). Contudo, a "cultura letrada, embora dependa da técnica utilizada na inscrição, não se define apenas pela existência desta técnica" (HAVELOCK, 1994, p. 59): a rigor, "a aquisição de letramento requer o desenvolvimento de diferentes habilidades, conhecimentos e atitudes. [...] Ler é um verbo transitivo; aprender a ler significa inevitavelmente aprender a ler alguma coisa. Ler e entender essa alguma coisa envolve trazer à luz uma grande quantidade de conhecimento ou esquemas de fundo" (WARSCHAUER, 2006, p. 72). No contexto da série proposta de artigos considera-se que o letramento televisual associado a $M C$ se dá analogamente ao caso dos gêneros do discurso introduzidos "em nossa experiência e em nossa consciência" (BAKHTIN, 1997, p. 301) a partir do contato com materialidades apresentadas na TV, na duração.

"[N]o início das transmissões de TV havia considerável espaço disponível [na grade de programação], gradualmente preenchido com inserções comerciais: grande parte destes anúncios que já ocorriam no rádio, agora sob forma de esquetes cômicos, filmes ou programas promocionais anunciava aparatos e utensílios domésticos. Tais veiculações acabaram por trazer demonstrações culinárias para a televisão, o que rapidamente ganhou contornos do programa [de receita] como conhecemos atualmente" (OLIVEIRA, 2014, p. 4). 
como certa, corriqueira ou não digna de uma consideração especial no cotidiano ${ }^{8}$ : afinal de contas, ainda que indubitavelmente relevante por constituir uma necessidade primária do ser humano, cozinhar é uma tarefa realizada diariamente em praticamente todos os domicílios ao redor do mundo.

Entende-se que analisar o sucesso de $M C$ envolve considerar o destaque que vem sendo atribuído à culinária e à gastronomia, associando esse destaque à forma como 0 ato de cozinhar tem sido tanto apresentado quanto representado na televisão: enquanto a apresentação envolve 0 aspecto icônico do programa (o que é assistido pelo público: a cozinha, os pratos elaborados etc.), a representação pode ser associada à perspectiva indicial e também simbólica (ou à interpretação da audiência a partir da observação dos elementos percebidos, remetendo a noções como a sofisticação dos pratos, a naturalidade dos participantes, a suposição de quem seria 0 vencedor da competição etc.). É nesse sentido que considerar o entorno associado ao programa é fundamental (especialmente no que diz respeito à ênfase atribuída ao ato de cozinhar na contemporaneidade que, conforme escrito anteriormente, não é detalhada neste primeiro artigo) e constitui tarefa-chave da produção da franquia. Ocorre que os produtores de programas colocam no "discurso televisivo [...] marcas de enunciação do cotidiano e da família" (SODRÉ, 1991, p. 224): as produções televisuais procuram elementos que possibilitem reconhecimento do real a partir do dia a dia da audiência no conteúdo veiculado. Ao conferir a existência da ênfase ao ato de cozinhar, associada à tendência de artificação do ambiente da cozinha, inferese que a proliferação de produções glocais de $M C$ e 0 sucesso associado ao programa podem ser pensados inicialmente a partir da espécie de espelhamento complexo (não direto ou literal) na TV de comportamentos constatados no cotidiano. Obviamente, não se considera neste artigo a existência de um simples e direto reflexo do cotidiano na TV. De fato, entende-se que o que ocorre é uma tensão dialética segundo a qual as produções de TV tanto vão obter referências no cotidiano para a criação de seus programas quanto, através dos programas criados a partir dessas referências, são veiculados conteúdos que auxiliam e promovem a redefinição de hábitos no cotidiano, em uma espécie de relação de influência mútua e contínua. Assim, a série proposta de artigos acessa um aspecto da "estrutura de sentimento" (WILLIAMS, 2001) em formação no momento em que os textos são escritos. Vale explicação da complexidade associada ao termo acessar no contexto deste artigo: ocorre que há reconhecida dificuldade para realizar 
análises enquanto uma cultura está sendo vivida (WILLIAMS, 1971, p. 18), em função da tendência em considerá-la como certa e estável. 0 verbo acessar é utilizado, então, para salientar que, na série proposta de artigos, procura-se superar tal dificuldade e conduzir análises da cultura do momento vivido, tentando abordar este momento em sua complexidade.

Complementarmente às marcas de enunciação, é desenvolvido um trabalho importante pela equipe de produção do programa que se inicia ainda na seleção dos participantes. Em certa medida, ilustrando a afirmação segundo a qual a "criação de significado é agora um ato editorial ou 'redacional', não um ato autoral" (HARTLEY, 2008, p. 182), a roteirista da primeira temporada de $M C$ Brasil comenta que várias decisões de produção são tomadas a partir dos vídeos enviados pelos candidatos quando de sua inscrição. Se, por um lado, consultores de gastronomia avaliam a competência dos potenciais competidores em relação ao ato de cozinhar propriamente dito, adicionalmente a equipe de produção de conteúdo utiliza os mesmos vídeos para analisar aspectos relacionados ao potencial desempenho televisivo dos candidatos:

Se [0 candidato inscrito] é um cozinheiro briIhante e que é travado em [apresenta dificuldades em relação à] câmera, eu não vou cortar essa pessoa. Se é uma pessoa muito boa em câmera que não cozinha nada, eu não vou chamar. [...] Se é um cozinheiro excelente, é um problema meu tirar a história dele [...]. Agora, se eu tenho pessoas que estão empatadas, [...] e tem uma pessoa que tem uma história excelente e vai ser um melhor personagem daí eu posso dar um pitaco [emitir uma opinião em relação a qual candidato escolher para participar], dizer que eu prefiro porque vai ser mais fácil de ter um programa de TV mais legal (ABADE, 2014, grifos nossos) $)^{9}$.

Assim, 0 ato de cozinhar recebe uma laminação, passa por uma transformação que tonaliza, isto é, transforma do ponto de vista da significação primária ou básica (GOFFMAN, 1974) a atividade cotidiana de preparar a comida com o uso de recursos narrativos amplificadores da produção de TV. Tal tonalização remete diretamente ao aspecto híbrido do programa referenciado anteriormente, o qual pode ser analisado utilizando o comentário da apresentadora da versão brasileira da franquia, para quem $M C$, "[i]ndependente de ele ser um formato de entretenimento - e é -, ele está baseado em outras coisas que não 'eu vou aparecer na televisão e ficar famosa'. Só vai ganhar isso aqui quem cozinhar direito" (PADRÃ0, 2014). Estabelecendo uma comparação com a franquia $B B$, Ana Paula Padrão comenta que os programas seriam diferentes pois "um é um reality $[B B]$, e outro é um talent $[M C]$. [...] Um talent é uma competição, eles não estão 
confinados, eles saem daqui, [...] não tem câmera atrás deles o tempo inteiro" (PADRÃO, 2014).

Apesar de a apresentadora considerar os programas como distintos, neste artigo se considera que a afirmação de Ana Paula, na verdade, atesta e confirma o caráter híbrido de $M C$ : enquanto a entrega de um produto resultante de um "cozinhar direito" para ser o vencedor na competição é aquilo que caracteriza, sem dúvida, um talento culinário ${ }^{10}$ (e justifica 0 uso do termo talent show por parte da jornalista para definir o programa), há que se observar a relevância também de caraterísticas associadas ao gênero reality show em $M C$ para compreender seu sucesso. Haveria, então, um híbrido entre reality e talent na franquia, e ambos os elementos compõem a receita que mistura genuínas habilidades culinárias (talent) com 0 comportamento programado e esperável do gênero telerrealidade (reality). Vale então uma explicação de como se considera que $0 M C$ articula os dois elementos para gerar significado para o público.

No caso dos programas de culinária, teria ocorrido 0 aprendizado para assistir ao programa em relação ao aspecto talent (ainda que haja uma diferença fundamental de $M C$ em relação aos programas de receita, associada à constatação de que não há explicações detalhadas para 0 público no reality show gastronômico no que diz respeito ao modo de preparo dos pratos).

Em $M C$ verifica-se uma tendência de produção dos alimentos mais relacionada à montagem e apresentação dos pratos do que ao preparo do alimento propriamente dito. Enquanto essa propensão, em certa medida, remete à artificação (e também pode ser associada ao que seria um signo mais complexo, mais desenvolvido no que se refere aos programas de culinária tradicionais), uma hipótese adicional para essa prevalência do visual em $M C$ pode ser elaborada em função de que os aspectos visual e auditivo constituem componentes sensoriais básicos para qualquer programa de TV. Apesar da obviedade do comentário, no caso de um programa cuja promessa enquanto formato tem muito a ver com os outros três sentidos (olfato, tato e sabor) - que são omitidos pela limitação técnica do meio -, os aspectos visual e auditivo tornam-se ainda mais fundamentais.

Adicionalmente ao letramento associado a programas de culinária, o aprendizado da audiência para compreender $M C$ enquanto telerrealidade parece envolver cinco características fundamentais. Inicialmente, a (i) relação entre público e personagens (os participantes) do programa que ultrapassa a mera admiração pelo prato elaborado: ocorre que as "empatias e as antipatias que você cria, você cria com o personagem [o participante do 
programa] e não com o prato que ele fez, inclusive porque TV não tem cheiro nem gosto" (PADRÃo, 2014). E para 0 estabelecimento de tal relação, a apresentadora Ana Paula Padrão exerce um papel fundamental ao entrevistar os personagens e seus familiares, inclusive fora do ambiente da cozinha $M C$ - tipicamente em suas residências. A jornalista explica que 0 apresentador do programa pode assumir uma postura

meramente cênica (alguém que dá as regrinhas do dia) [como é o caso dos apresentadores típi$\cos$ - nas produções locais da franquia que fazem uso de um apresentador, além dos chefs] ou pode ser uma pessoa que efetivamente se envolve com o formato, conhece os participantes, faz o perfil dos participantes, começa a mostrar [os participantes] em casa, que é o que eu chamo de cronista [...] [que é o caso de Ana Paula Padrão, na produção brasileira da franquia]. [0 cronista então teria como objetivo] demonstrar para 0 telespectador algo que para nós [profissionais relacionados com a produção do programa] já é óbvio, porque a gente está aqui todo dia, mas que talvez o telespectador não tenha visto (PADRÃO, 2014, grifo nosso).

Além das entrevistas conduzidas por Padrão (as quais constituem uma adaptação local para 0 formato standard da franquia), há que assinalar que ocorrem minientrevistas com os cozinheiros amadores participantes durante o preparo dos pratos, que são veiculadas ao longo do programa, e que também contribuem com o estabelecimento e desenvolvimento da citada relação com a audiência. Merece destaque ainda que tais minientrevistas estão presentes em todas as produções de $M C$ : a complexidade envolvida nessas produções discursivas justifica analisá-las no segundo artigo desta série, quando serão discutidos aspectos relativos ao solilóquio típico do gênero.

Além do aspecto do personagem, convém destacar a manifestação do que poderia ser nomeado como 0 (ii) tempero narrativo do programa: particularmente, a existência de restrições que tornam mais complexa a realização das tarefas. No caso de $M C$, tais restrições podem ser associadas à necessidade de utilização de ingredientes desconhecidos ou inusitados para um cozinheiro amador, mas, frequentemente, estão vinculadas ao tempo limitado e fortemente controlado para o preparo dos pratos. Como terceiro fator, apontamos a (iii) dimensão sonora do programa, que se manifesta no estilo hiperbólico de falar dos chefs (tanto comentários durante o preparo quanto o juízo que emitem no ato da degustação dos pratos, ou ainda em seus gestos): percebe-se outra espécie de compensação audiovisual à ausência dos sentidos do tato, olfato e paladar na TV. Como quarto fator fundamental, pode ser apresentada a (iv) interatividade. Ainda que em $M C$ não haja um mecanismo de votação por parte da audiência para definição dos rumos do programa (inclusive porque 0 conteúdo veiculado é previamente gravado), a participação do público via postagens nas redes sociais - tuítes que são apresentados sobre as imagens dos participantes do programa (no caso da emissão brasileira, mas não para a versão argentina) - enquanto 0 programa é veiculado promove um efeito de 'ao vivo' na transmissão (MARQUIONI; OLIVEIRA, 2015b). Tal efeito, indubitavelmente, contribui com 
0 estabelecimento de tensão durante 0 programa, proporcionando uma torcida/empolgação (típica em um reality show, mas que tem pouco sentido em um programa de receitas culinárias): parece que via os reality shows a audiência foi preparada em relação a como assistir ao (ou como participar do) programa. Finalmente, outro elemento fundamental remete ao (v) aspecto semiótico observável em $M C$ - particularmente em relação ao signo indicial ou índice (que se define nos seguintes termos):

0 que 0 signo (indicial) tem virtualmente que fazer para indicar seu objeto - e fazê-lo seu - tudo o que ele deve fazer é simplesmente captar os olhos do intérprete e virá-los à força em direção do objeto significado: isso é o que faz uma batida na porta, ou um alarme ou outra campainha [...] Trata-se de uma pura compulsão fisiológica, nada mais do que isso (CP 5.554 ${ }^{11}$ ).

Na perspectiva semiótica, o modo de significar que é hegemônico, no qual se baseia fundamentalmente a atração exercida por um programa do gênero ao qual pertence 0 formato de $M C$ para seu público, é a representação audiovisual do aspecto factual humano, 0 surgimento recorrente de comportamentos valorados enquanto sejam ou não fatos genuínos, qual seja, a evidência de algo real que, no gênero documentário, por exemplo, existiria mesmo se não fosse filmado ou representado para o público do programa. Essa é a premissa especialmente no gênero de documentário chamado direct cinema, aliás. Esse elemento é representado nas falas, mas, ainda mais persuasivamente, nos gestos dos participantes e dos chefs em interação com aqueles. Esses aspectos da encenação do programa criam uma atmosfera, um feeling vago, porém inconfundível, que é a aura de um reality show como o formato de $M C$ : seu index appeal (ANDACHT, 2003, p. 41-64). No funcionamento semiótico de $M C$, como também o de seu parente distante e estigmatizado, a pornografia, compensa-se a ausência marcante daquilo que é a promessa fundamental e última do formato: 0 contato íntimo com a matéria visualizada ao longo de quase todo o tempo da exibição, por meio da amplificação extrema do ato de consumo e seus efeitos físicos. A visão próxima do chef degustando, saboreando e engolindo desempenha, de modo emblemático, o papel de evidência material e inegável do que seria 0 impacto da experiência física mesma. 0 recurso de exibir de modo triplicado - 0 ato de degustação, mastigação e olfato - e de amplificar esse efeito indicial, através da visão bem próxima do corpo do participante que está sendo julgado (e, com frequência, também nos corpos dos outros participantes que assistem a esse julgamento inapelável e que são enfocados pelas câmeras de $M C$ ), está no núcleo narrativo do programa, como acontece com a visão do pulso acelerado dos competidores de BB Brasil em dias de eliminação. Entende-se que o componente factual fornece a 
característica distintiva do reality gastronômico e de modo ainda mais evidente de seu parente tão polêmico, o reality Big Brother em qualquer uma de suas produções do mundo. A dúvida recorrente sobre a autenticidade dos sentimentos revelados pelos gestos, pelas ações, e, muito especialmente, pelas manifestações emocionais e fisiológicas dos participantes faz parte do consumo de $M C$ : como poderá reagir o participante $\mathrm{X}$, quando o chef/ jurado Y rejeitar/elogiar seu prato? Pode-se pensar no espaço ‘sacro' do pódio (onde aguardam como se fossem oráculos inexoráveis e infalíveis os três chefs/jurados) como o cenário principal do grande salão, onde cozinham os aprendizes de $M C$. Tal pódio gastronômico é o centro desse universo, uma espécie de altar onde toda a frenética atividade associada à criação dos pratos atinge 0 ponto mais alto; esse lugar é o espaço que o público acompanha com a maior atenção, porque não quer perder nenhum detalhe do que acontece ritualmente lá.

Eis 0 âmago da significação indicial do reality em seu formato gastronômico, que conduz 0 espectador a procurar por índices de um "efeito de real" (BARTHES, [1968] 1984), seja em aspectos mais ordinários - como o fato visual da fumaça, ou a menção pelo apresentador do programa ao cheiro inconfundível de algo queimado quando um participante esquece algo na panela sobre o fogão ( 0 que proporciona uma tonalidade escura - percebido visualmente pelo público - associada a um cheiro forte e desagradável - notado pelo aspecto dos rostos dos participantes - e caracterizando a distração como responsável por produzir um alimento já não mais comestível), ou em contextos associados à acirrada concorrência, às diversas e conflitivas personalidades, às reações de cada participante perante cada desafio, produzindo, por sua vez, as reações dos espectadores que, inevitavelmente, vão acabar escolhendo competidores por quem torcer. 0 índice constitui ainda um fato que "abre com vigor seu caminho para a existência (the fact fights its way into existence); porque ele existe em virtude das oposições que ele envolve" (CP 1.432). Eventualmente, o conceito pode ser entendido como uma boa alternativa para descrever, de modo geral, 0 fenômeno que se manifesta pela cor vermelha e pela umidade crescente que brilha nos olhos do competidor da segunda temporada brasileira, 0 nordestino Cristiano, quando recebe elogios de dois chefs/jurados do programa e compreende-se, assim, que ele fica muito emocionado (conforme comenta em seguida no monólogo que regularmente é inserto na ação dramática de $M C)^{12}$.

Ocorre que esses cinco fatores ${ }^{13}$, definitivamente, auxiliam a criar um estado de tensão que

120 fato foi apresentado no Episódio 05 da Temporada 02 da produção brasileira da franquia. Disponível em: <http:// entretenimento.band.uol.com.br/masterchef/2015/videos/episodios/episodio-05/15508875/5-eliminacao-da-prova-damandioca.html >. Acesso em: 25 out. 2015.

13 Conforme mencionado, os fatores seriam a (i) relação entre público e personagens, o (ii) tempero narrativo, a (iii) dimensão sonora, a (iv) interatividade e 0 (v) aspecto semiótico (indicial). 
espetaculariza a ação cotidiana de cozinhar e afastam $M C$ de uma emissão televisual típica de um programa culinário tradicional: 0 contexto permite inferir que, paradoxalmente, cozinhar parece mesmo constituir um componente periférico no programa. Desse modo, reforçase 0 caráter híbrido: em uma análise de $M C$ no nível mais capilar, enquanto produto televisual, 0 aspecto talent (que, indubitavelmente, contribui para o letramento do público a partir dos programas de receita), ao ser operacionalizado em conjunto com 0 aspecto reality contribui para 0 sucesso mundial de $M C$.

Em boa medida, o programa encena ordálias da identidade humana - como acontece no caso de Big Brother - que são inseparáveis do elemento talento (particularmente, um talento unido à geração de produto indispensável para manter cotidianamente a vida), gera uma narrativa atraente porque, além do resultado material e visível - e até certo ponto audível - dos esforços técnicos e práticos dos participantes, os espectadores são testemunhas privilegiadas da ordem da interação, essa região que, de forma pioneira, começou a pesquisar Goffman (1959) com seu modelo dramatúrgico da apresentação do si mesmo na vida de cada dia. Dessa maneira, um âmbito tradicionalmente oculto, 0 qual poderia ser concebido como fazendo parte dos bastidores, do 'backstage' primordial onde se prepara o comportamento de fachada, a vida pública, qual seja, a cozinha. 0 espaço onde se fabrica um componente fundamental, mas não visível daquilo que nos permite agir, trabalhar, enfim, atuar com normalidade como seres competentes perante os outros, abre-se de modo espetacular à visão do público nos episódios de $M C$. A lição que recebe quem assiste cada semana ao reality-talent show tem pouco a ver com os pratos que essas pessoas vão fazer para suas refeições, e muito mais com as reflexões que surgem sobre a própria identidade na era da artificação da cozinha, da transformação estética daquilo que era considerado antes como sendo apenas um elemento utilitário de nossa vida. Espreitando com grande atenção, tentando enxergar além das fileiras de fogões, panelas, frigideiras, louça, dos variados utensílios e dos exóticos ingredientes, o relacionamento difícil, conflituoso desses aspirantes a grande cozinheiro, que é causado pelas provas criadas pelo programa para sua narrativa, o espectador procura os indícios que lhe permitam separar 0 autêntico do falso, 0 verdadeiro do encenado, não apenas na vida dos outros, mas também na própria existência. A magnífica e elegante cozinha de MasterChef é mais uma encenação da melocrônica que introduziu no fim do século XX seu polêmico antepassado midiático, o Big Brother da Endemol, um convite a espreitar a alma em um contexto que parece o menos indicado possível para que aconteça tal revelação.

Para avançar as análises, considera-se necessário expandir as reflexões para além do aspecto da produção de TV per se (abordado no presente 
artigo). Desta forma, além do contexto cultural conforme ele foi considerado neste primeiro trabalho, é relevante complexificar um aspecto marcante do gênero reality show (associado diretamente ao tempero narrativo) para pensar, conceitualmente, o sucesso de $M C$. Tal aspecto parece mesmo atuar no sentido de reforçar 0 estabelecimento de identidades, incluindo o acesso à intimidade familiar que circunda a produção: trata-se do solilóquio, tema central do segundo artigo desta série.

\section{Referências}

ABADE, Daniela. Entrevista presencial concedida pela roteirista da primeira temporada de MasterChef Brasil para Caroline Cavalcanti de Oliveira e Carlos Eduardo Marquioni. São Paulo, 20 set. 2014.

ANDACHT, Fernando. Big Brother te está mirando. La irresistible atracción de un reality show global. In: PAIVA, R. (org.). Ética, cidadania e imprensa. Rio de Janeiro: Mauad, 2002. pp. 63-100.

El reality show: una perspectiva analítica de la televisión. Buenos Aires: Grupo Editorial Norma, 2003.

Fight, love and tears: an analysis of the reception of Big Brother in Latin America. In MATHIJS, E., JONES, J. (eds.). Big Brother International: Formats, critics and publics. Londres: Wallflower Press, 2004. pp. 123-139.

BAKHTIN, Mikhail. Estética da criação verbal. São Paulo: Martins Fontes, [1979] 1997.

BARTHES, Roland. 0 efeito de real. In:

0 rumor da língua. Lisboa: Edições 70, 1984.

BR00KER, Charlie. MasterChef is the best television show in broadcasting history, if you ignore all the other ones. Disponível em: < http://www.theguardian. com/commentisfree/2014/apr/21/masterchef-charliebrooker-grimm-fable > . Acesso em: 27 jul. 2015.

FIGUEIRÔA, Alexandre; BEZERRA, Cláudio; FECHINE, Yvana. 0 documentário como encontro: entrevista com o cineasta Eduardo Coutinho. In: Galáxia, № 6, pp. 213-229, 2003.

FINAL do "MasterChef" lidera audiência por 21 minutos e bate recorde. Disponível em: < http:// televisao.uol.com.br/noticias/redacao/2015/09/16/finaldo-masterchef-lidera-audiencia-por-21-minutos-e-baterecorde.htm >. Acesso em: 22 out. 2015.

\section{GOFFMAN, Erving. The presentation of self in}

everyday life. New York: Doubleday Anchor Books, 1959.

Frame Analysis: an essay on the organization of experience. New York: Harper \& Row, 1974.

HARTLEY, John. Television truths. Malden, Oxford e Carlton: Blackwell Publishing, 2008.

\section{HAVELOCK, Erick A. A revolução da escrita na} Grécia e suas conseqüências culturais. São Paulo: Editora da UNESP/Paz e Terra, 1994.

HILL, Annette. Big Brother: The real audience. In:

Television \& New Media, vol. 3, n. 3, ago. 202, p. 323-340, 2002.

MARQUIONI, Carlos Eduardo; OLIVEIRA, Caroline Cavalcanti de. Sobre novas formas de manipulação do tempo na televisão (ou Redefinindo a noção de TV 'ao vivo’ via redes sociais). XIV Congresso Internacional Ibercom 2015. Anais... São Paulo: USP, 2015a.

Para além da competição: consumindo afetos como cultura material no programa MasterChef (análises e reflexões iniciais). In: Conexão, UCS, vol. 15, n 28 (no prelo), jul./dez 2015, Caixas do Sul, 2015b.

MASTERCHEF BR. Disponível em: < http:// entretenimento.band.uol.com.br/masterchef/> . Acesso em: 28 ago. 2015. 
'MASTERCHEF' REESTREIA com audiência 40\% maior em relação à primeira temporada. Disponível em: < http:// f5.folha.uol.com.br/televisao/2015/05/1631375-masterchefreestreia-com-audiencia-40-maior-em-relacao-aprimeira-temporada.shtml>. Acesso em: 24 ago. 2015. MILLER, Daniel. Stuff. Cambridge: Polity Press, 2010. OLIVEIRA, Caroline Cavalcanti. Das apropriações de modelos televisuais pela internet: reconfigurações midiáticas do programa de receita. XXXVII Intercom. Anais... Foz do Iguaçu: UDC, 2014.

PADRÃO, Ana Paula. Entrevista presencial concedida pela apresentadora da primeira temporada de MasterChef Brasil para Caroline Cavalcanti de Oliveira e Carlos Eduardo

Marquioni. São Paulo, 20 set. 2014.

ROBERTSON, Ronald. Glocalization: time-space and homogeneity-heterogeneity. In: FEATHERSTONE, Mike; SCOTT, Lash; ROBERTSON, Ronald (eds).

Global Modernities. London: Sage Publications, 1995. pp. 25-44.

SHAPIR0, Roberta. Que é artificação? In: Sociedade e Estado, Brasília, v. 22, n. 1, p. 135-151, jan./abr. 2007.

SHINE GROUP. Original producer: Shine TV in association with Ziji Productions. Disponível em: $<$ http://www.shinegroup.tv/key-shows/masterchef $>$. Acesso em: 27 jul. 2015.

SODRÉ, Muniz. Álbum de família. In: NOVAES, Adauto (org.). Rede imaginária: televisão e democracia. São Paulo: Companhia das Letras, 1991. p. 222-228.

STILETANO, Marcelo. La final de MasterChef que no fue y el enojo de Juan José Campanella. La Natión, 20 ago. 2015. Personajes.tv La Tele Nuestra. Disponível em: < http://personajes.lanacion.com.ar/1820738-lafinal-de-masterchef-que-no-fue-y-el-enojo-de-juan-josecampanella >. Acesso em: 2 set. 2015.

WARSCHAUER, Mark. Tecnologia e inclusão social: A exclusão digital em debate. São Paulo: Editora Senac, 2006.
WILLIAMS, Raymond. Drama from Ibsen to Brecht. London: Chatto \& Windus, [1952, 1968] 1971. The long revolution. Peterborough: Broadview Press Ltd., [1961] 2001. 
Playing with food: MasterChef and the televisual devices

\section{that transform an everyday} activity into a spectacle

\section{Abstract}

The article analyzes the program MasterChef as a hybrid format between a reality show and a talent show. Its success is construed as the outcome of a TV literacy that in its present stage gives the audience access to contemporary culinary artification. Besides immanent semiotic analysis, we use material elicited in interviews with the production team of the first Brazilian edition. The result would indicate that practical culinary aspects are not the main attraction of the program. The format has five components that could account for its popularity; foremost among them are the trials by ordeal involving the identity of participants in tests of psychological and culinary resilience.

\section{Keywords}

reality show; literacy; indexical semiotic.

Jugando con la comida: MasterChef y los recursos televisuales que convierten en espectáculo una actividad cotidiana

\section{Resumen}

El artículo analiza el programa MasterChef como un formato híbrido entre el reality show y el talent show. Se considera su éxito como relacionado a la alfabetización televisual que en su fase actual expone al público a la artificación culinaria contemporánea. Además del análisis semiótico inmanente, se usa material obtenido en entrevistas con la producción de la primera edición brasileña. El resultado sería que el aspecto culinario práctico no constituiría la principal atracción del programa. El formato tendría cinco componentes que explicarían su popularidad; se destaca entre ellos la ordalía de la identidad de los participantes en pruebas de resistencia tanto psicológica como culinaria.

\section{Palabras clave}

reality show; alfabetización; semiótica indicial. 


\section{Expediente}

A revista E-Compós é a publicação científica em formato eletrônico da Associação Nacional dos Programas de Pós-Graduação em Comunicação (Compós). Lançada em 2004, tem como principal finalidade difundir a produção acadêmica de pesquisadores da área de Comunicação, inseridos em instituições do Brasil e do exterior.

\section{E-COMPÓS I www.e-compos.org.br I E-ISSN 1808-2599}

Revista da Associação Nacional dos Programas de Pós-Graduação em Comunicação. Brasília, v.19, n.2, maio/ago. 2016. A identificação das edições, a partir de 2008, passa a ser volume anual com três números. Indexada por Latindex I www.latindex.unam.mx

\section{CONSELHO EDITORIAL}

\section{Alexandre Farbiarz, Universidade Federal Fluminense, Brasi}

Alexandre Rocha da Silva, Universidade Federal do Rio Grande do Sul, Brasil Ana Carolina Escosteguy, Pontifícia Universidade Católica do Rio Grande do Sul, Brasil Ana Carolina Rocha Pessôa Temer, Universidade Federal de Goiás, Brasil Ana Regina Barros Rego Leal, Universidade Federal do Piauí, Brasil Andrea França, Pontifícia Universidade Católica do Rio de Janeiro, Brasil André Luiz Martins Lemos, Universidade Federal da Bahia, Brasil Antonio Carlos Hohlfeldt, Pontifícia Universidade Católica do Rio Grande do Sul, Brasil Arthur Ituassu, Pontifícia Universidade Católica do Rio de Janeiro, Brasil Álvaro Larangeira, Universidade Tuiuti do Paraná, Brasil

Ângela Freire Prysthon, Universidade Federal de Pernambuco, Brasil César Geraldo Guimarães, Universidade Federal de Minas Gerais, Brasil Cláudio Novaes Pinto Coelho, Faculdade Cásper Líbero, Brasil Daisi Irmgard Vogel, Universidade Federal de Santa Catarina, Brasil Denize Correa Araujo, Universidade Tuiuti do Paraná, Brasil Eduardo Antonio de Jesus, Pontifícia Universidade Católica de Minas Gerais, Brasil Daniela Zanetti, Universidade Federal do Espírito Santo, Brasil Eduardo Vicente, Universidade de São Paulo, Brasil

Elizabeth Moraes Gonçalves, Universidade Metodista de São Paulo, Brasil Erick Felinto de Oliveira, Universidade do Estado do Rio de Janeiro, Brasil Francisco Elinaldo Teixeira, Universidade Estadual de Campinas, Brasil Francisco Paulo Jamil Almeida Marques, Universidade Federal do Paraná, Brasil Gabriela Reinaldo, Universidade Federal do Ceará, Brasil

Goiamérico Felício Carneiro Santos, Universidade Federal de Goiás, Brasil Gustavo Daudt Fischer, Universidade do Vale do Rio dos Sinos, Brasil Herom Vargas, Universidade Municipal de São Caetano do Sul, Brasil Itania Maria Mota Gomes, Universidade Federal da Bahia, Brasil Janice Caiafa, Universidade Federal do Rio de Janeiro, Brasil Jiani Adriana Bonin, Universidade do Vale do Rio dos Sinos, Brasil
José Afonso da Silva Junior, Universidade Federal de Pernambuco, Brasil José Luiz Aidar Prado, Pontifícia Universidade Católica de São Paulo, Brasil Juçara Gorski Brittes, Universidade Federal de Ouro Preto, Brasil Kati Caetano, Universidade Tuiuti do Paraná, Brasil Lilian Cristina Monteiro França, Universidade Federal de Sergipe, Brasil Liziane Soares Guazina, Universidade de Brasilia, Brasil Luíza Mônica Assis da Silva, Universidade de Caxias do Sul, Brasil Luciana Miranda Costa, Universidade Federal do Pará, Brasil Malena Segura Contrera, Universidade Paulista, Brasil Monica Martinez, Universidade de Sorocaba, Brasil Maria Ataide Malcher, Universidade Federal do Pará, Brasil Marcia Tondato, Escola Superior de Propaganda e Marketing, Brasil Marcel Vieira Barreto Silva, Universidade Federal da Paraiba, Brasil Maria Clotilde Perez Rodrigues, Universidade de São Paulo, Brasil Maria das Graças Pinto Coelho, Universidade Federal do Rio Grande do Norte, Brasil Mauricio Ribeiro da Silva, Universidade Paulista, Brasil

Mauro de Souza Ventura, Universidade Estadual Paulista, Brasil Márcio Souza Gonçalves, Universidade do Estado do Rio de Janeiro, Brasil Micael Maiolino Herschmann, Universidade Federal do Rio de Janeiro, Brasil Mirna Feitoza Pereira, Universidade Federal do Amazonas, Brasil Nísia Martins Rosario, Universidade Federal do Rio Grande do Sul, Brasil Potiguara Mendes Silveira Jr, Universidade Federal de Juiz de Fora, Brasil Regiane Regina Ribeiro, Universidade Federal do Paraná, Brasil Rogério Ferraraz, Universidade Anhembi Morumbi, Brasil Rose Melo Rocha, Escola Superior de Propaganda e Marketing, Brasil Rozinaldo Antonio Miani, Universidade Estadual de Londrina, Brasil Sérgio Luiz Gadini, Universidade Estadual de Ponta Grossa, Brasil Simone Maria Andrade Pereira de Sá, Universidade Federal Fluminense, Brasil Veneza Mayora Ronsini, Universidade Federal de Santa Maria, Brasil Walmir Albuquerque Barbosa, Universidade Federal do Amazonas, Brasil
COMISSÃO EDITORIAL Eduardo Antonio de Jesus, Pontifícia Universidade Católica de Minas Gerais, Brasil I Osmar Gonçalves dos Reis Filho, Universidade Federal do Ceará, Brasi

CONSULTORES AD HOC Alexandre Almeida Barbalho, Universidade Estadual do Ceará, Brasil | Alexandre Rocha da Silva, Universidade Federal do Rio Grande do Sul, Brasil | Bruno Souza Leal, Universidade Federal de Minas Gerais, Brasil I Carlos Eduardo Franciscato, Universidade Federal do Sergipe, Brasil I Eneus T. Barreto Filho, Universidade de São Paulo, Brasil I Felipe da Costa Trotta, Universidade Federal Fluminense, Brasi | Henrique Codato, Universidade Federal do Ceará, Brasil I Ines S. Vitorino Sampaio Universidade Federal do Ceará, Brasil I Jairo Getulio Ferreira, Universidade do Vale do Rio dos Sinos, Brasil I Juliana Freire Gutmann, Universidade Federal da Bahia, Brasil | Júlio César M. Pinto, Pontifícia Universidade Católica de Minas Gerais, Brasil I Lucrecia D. Ferrara, Pontifícia Universidade Católica de São Paulo, Brasil I Marcio V. Serelle, Pontifícia Universidade Católica de Minas Gerais, Brasil I Maria Ignes C. Magno, Universidade Anhemb Morumbi, Brasil I Maria Lilia Dias de Castro, Universidade Federal de Santa Maria, Brasil | Mozahir S. Bruck, Pontifícia Universidade Católica de Minas Gerais, Brasil I Potiguara M. da Silveira Junior, Universidade Federal de Juiz de Fora, Brasil I Sandra Maria L. P. Gonçalves, Universidade Federal do Rio Grande do Sul, Brasil I Suzana Kilpp, Universidade do Vale do Rio dos Sinos, Brasil I Tiago Q. Fausto Neto, Universidade de Brasília, Brasil I Vera Regina V. Franca, Universidade Federal de Minas Gerais, Brasil I Virginia P. S. Fonseca, Universidade Federal do Rio Grande do Sul, Brasil

EQUIPE TÉCNICA ASSISTENTE EDITORIAL Márcio Zanetti Negrini REVISÃo DE TEXTOS Press Revisão I EDITORAÇÃO ELETRÔNICA Roka Estúdio

\section{COMPÓS I www.compos.org.br}

Associação Nacional dos Programas de Pós-Graduação em Comunicação

Presidente

Edson Fernando Dalmonte

Programa de Pós-Graduação em Comunicação

e Cultura Contemporânea - UFBA

edsondalmonte@uol.com.br

Vice-presidente

Cristiane Freitas Gutfreind

Programa de Pós-Graduação em Comunicação Social - PUC-RS cristianefreitas@pucrs.br

Secretário-Geral

Rogério Ferraraz

Programa de Pós-Graduação em Comunicação

Universidade Anhembi Morumbi

rogerioferraraz@anhembimorumbi.edu.br

CONTATO I revistaecompos@gmail.com 